\title{
Reform and Practice of Mathematical Modeling and Mathematical Experiment Course in Independent College
}

\author{
Xiaoling Li", Wenjuan Zhai \\ Haibin College, Beijing Jiaotong University, Huanghua, China \\ Email address: \\ xlli@bjtuhbxy.cn (Xiaoling Li), wjzhai@bjtuhbxy.cn (Wenjuan Zhai) \\ ${ }^{*}$ Corresponding author
}

\section{To cite this article:}

Xiaoling Li, Wenjuan Zhai. Reform and Practice of Mathematical Modeling and Mathematical Experiment Course in Independent College. Science Innovation. Vol. 4, No. 2, 2016, pp. 72-76. doi: 10.11648/j.si.20160402.19

Received: March 25, 2016; Accepted: April 8, 2016; Published: April 18, 2016

\begin{abstract}
Based on the educational background of independent college and the relevant previous studies and researches, this paper discusses the importance of mathematical modeling and mathematical experiment course in independent college. Meanwhile, based on the investigation and study of the characteristics of the independent college students, this paper points out the deficiency of the curriculum in independent college and according to the experience of the relevant practices, it also summarizes the reform ideas and measures about the mathematical modeling and mathematical experiment curriculum.
\end{abstract}

Keywords: Independent College, Mathematical Modeling, Mathematics Experiments, Reform in Education

\section{独立学院数学建模及数学实验课程实践改革}

\author{
李晓玲*, 翟文娟 \\ 海滨学院, 北京交通大学, 河北黄骅, 中国 \\ 邮箱 \\ xlli@bjtuhbxy.cn(李晓玲), wjzhai@bjtuhbxy. cn(翟文娟)
}

中文摘要: 本文以独立学院为背景, 通过对相关文献的学习归纳, 论述了独立学院开设数学建模及数学实验课程的重 要性。在充分调查和研究了独立学院学生特点的基础上, 指出了课程开设中的不足, 并根据相关实践经验, 总结了数 学建模及数学实验课程改革的意见和措施。

关键词: 独立学院, 数学建模, 数学实验, 课程改革

\section{1. 引言}

随着中国高等教育模式的改革和发展, 独立学院作为 一种崭新的办学模式, 已经成为中国高等教育的重要组成 部分。中国教育部 “26号令” 第二条明确指出：“本办法 所称独立学院, 是指实施本科以上学历教育的普通高等学 校与国家机构以外的社会组织或者个人合作, 利用非国家 财政性经费举办的实施本科学历教育的高等学校。” 以北
京交通大学海滨学院为例, 该校以建设特色鲜明的高水平 应用技术型大学, 培养高素质工程技术和经营管理人才为 总目标 $[14]$ 。

数学建模即是将一个实际问题根据特定的需要, 做一 些必要的假设, 翻译成数学语言, 利用数学的方法结论对 这个数学问题进行分析和计算, 最后将所求的结果回归实 际, 解答实际问题的过程。它是一切应用科学的基础 [4]。 数学实验是借助数学软件, 结合所学的数学知识解决实际 
问题的一门实践课。中科院院士、北京大学的姜伯驹教授 认为 “应该通过数学实验课程, 学生在教师的指导下, 用 数学软件探索数学理论或应用实践, 或者通过探索自己的 想法获得真知。” 这种方式变被动的灌输为主动的参与, 有利于培养学生的独立工作能力和创新精神” [16]。可见, 数学建模和数学实验思想的渗透能够更好的培养学生的 实践能力, 应变能力, 创新能力, 符合独立学院的办学宗 旨和办学模式, 对提高独立学院的办学水平有着重要意义。

并且, 传统的大学数学课程教学抽象性强, 重理论轻 实践, 能够很好的培养学生的逻辑思维能力, 但明显实践 环节训练较少, 缺少 “应用性”, 大部分学生也只是被动 接受所学知识, 将数学知识隔离开来, 缺少发现问题, 分 析问题, 解决问题的能力。数学建模课程和数学实验课程 的开设则是让学生体会数学的应用性, 培养学生的创新思 维和独立思考能力。从这个角度讲, 针对独立学院学生特 点, 改革和完善数学实验和数学建模课程的教学模式是迫 切而必须的, 同时, 通过对数学实验和数学建模课程的改 革, 也为独立学院大学数学课程教学改革提供依据。

\section{2. 数学建模和数学实验课程的开设情况及存在 问题}

独立学院多以培养应用技术型人才为主要目标, 开设 专业也多是应用型专业而非研究型专业, 数学建模和数学 实验课程主要是作为公共选修课开设, 全院二年级及其以 上年级的理工类专业学生均可选, 每学期开设 32 学时, 班 级容量为 120 人。表 1 为北京交通大学海滨学院 2014 级开设 专业情况表及选修情况。由统计数据可以看出, 各系选修 人数只占该系人数的 $10 \%$ 左右并且分布不均匀, 尤其像艺 术系英语系这样的专业基本上对这样的课程没有兴趣。

表1 海滨学院 14 级学生数学类选修课情况统计表。

\begin{tabular}{lll}
\hline 系别名称及人数 & $\begin{array}{l}\text { 选修数学建模人数 } \\
\text { 及占比 }\end{array}$ & $\begin{array}{l}\text { 选修数学实验人 } \\
\text { 数占比 }\end{array}$ \\
\hline 自控系 $(340 人)$ & $29(8.5 \%)$ & $2(0.6 \%)$ \\
计算机系 $(170 人)$ & $3(1.7 \%)$ & $0(0 \%)$ \\
土建系 $(306$ 人) & $28(9.1 \%)$ & $18(5.9 \%)$ \\
经济管理系 $(782 人)$ & $55(7.0 \%)$ & $40(5.1 \%)$ \\
英语系 $(102$ 人) & $0(0 \%)$ & $4(3.9 \%)$ \\
艺术系 $(238$ 人) & $0(0 \%)$ & $2(0.8 \%)$ \\
机械类 $(340$ 人) & $35(10.2 \%)$ & $40(11.7 \%)$ \\
电信系 $(418$ 人) & $61(14.5 \%)$ & $46(11.0 \%)$ \\
交通运输系 $(204 人)$ & $22(10.7 \%)$ & $84(41.1 \%)$ \\
化工系 $(78 人)$ & $7(8.9 \%)$ & $0(0 \%)$ \\
\hline
\end{tabular}

由于实践时间短, 经验少, 教学过程还主要模仿其主 干学校的方式, 偏向研究型教学, 也造成了诸多问题。

\section{1. 教学内容多, 学习时间少}

大部分高校的数学建模课程以姜启源教授的《数学模 型》为主要参考教材, 分为数学模型简介, 初等数学模型, 简单优化模型, 数学规划模型, 微分方程模型, 离散模型, 概率模型, 统计规律模型等 [7], 内容丰富, 具有生活气 息, 能够让学生充分体会数学的普遍适用性。但是对于独 立学院的学生而言, 他们的数学功底薄弱, 有些数学知识
是他们所不具备的, 听起来往往是囫囵吞束, 还未弄懂怎 么回事, 课程就结束了, 更谈不上了解其知识对后续课程 的作用及产生的影响。

数学实验课程同其他实验课程一样, 是一门实践课 程, 不同之处是数学实验是指借助数学软件, 结合所学 的数学知识来解决实际应用问题, 这就需要学生们首先 要了解数学软件的操作, 大部分学校主要是以mat lab为 主进行教学, 很多学生能够通过学习, 进一步体会数学 的思想, 并能够掌握更加有效率的用数学知识解决实际 问题的方法。但是实验课更重要的是以学生为主进行实 践, 由于课时限制, 学生们的实践时间就会相应压缩, 教师无法做到每个人都去指导的话, 就会有很大一部分 同学无法真正的掌握其内涵。

\section{2. 教学方法单一, 考核方式片面}

由于条件和时间的限制, 数学建模和数学实验课程教 学方法还多以讲授法为主, 学生讨论和实践为辅。表 2 是 张文博等在《数学建模与数学实验课程调查报告》中对 403 所院校数学建模课程考核方式的统计情况, 可以看出各高 校考核方式多以提交结课报告或者论文形式为主。而独立 学院学生自主学习能力较差, 在缺乏有力的监督和考核方 式下, 很难做到自主研学, 课外实践, 这也是导致学生们 学习效果不佳的原因之一。

表2 403所院校数学建模课程考核方式统计表 [7]。

\begin{tabular}{lll}
\hline 选项 & 被访者比例\% & 被访者数量 \\
\hline 试卷 & 33.50 & 135 \\
专题报告 & 41.44 & 167 \\
结业论文或大作业 & 34.74 & 141 \\
\hline
\end{tabular}

\section{3. 师资队伍经验缺乏，硬件设施资料等不完善}

一方面, 独立学院的教师组成基本上都是 “两头大, 中间小”即退休老教授和青年教师多, 中年教师少的局面。 退休老教授的学识和阅历都很丰富, 但是他们精力有限, 对一些数学软件的应用能力有限; 青年教师精力充沛, 学 习能力较强, 但是教学经验不足, 知识水平有限。

另一方面, 独立学院各门课程都在探索和改革中, 数 学建模课程的发展更是相对滞后, 据了解很多学校没有独 立的数学建模实验室更没有先进的数学建模软件工具及 图书资料, 很难为学生们提供一个良好的学习环境。

\section{3. 对数学建模和数学实验课程的改革及实践}

\section{1. 明确教学目的, 改革教学内容}

\subsection{1. 以普及思想, 培养兴趣为重点, 而不是培养研究 型人才}

以北京交通大学海滨学院为例, 随机选取了 400 名学 生进行统计调查, 在毕业意向的调查中选择毕业后直接就 业的学生占到 $93 \%$, 选择出国或者考研的学生只有 7\%（见 图1); 在回答 “如果把人的精力分为 10 份, 你愿意用在 学习上的精力有几份, 时, 回答3份, 5份, 8份, 10份的 人数分别是 $103,189,76,32$; 有 $32.8 \%$ 的同学对所选专 
业不敢兴趣, 但是有 $56.9 \%$ 的同学表示愿意参加各类文体 活动及社团活动等。以上调查结果表明独立学院的学生思 维敏捷活跃, 但是学习能力差, 学习兴趣不够, 知识基础 薄弱, 而且今后要从事研究型事业的同学也少之甚少。所 以, 作为针对独立学院学生的数学建模和数学实验课程重 点不在培养学生的研究性思维, 而是在于 ‘用数学” 思想 的普及, 激发学生学习数学的兴趣, 让学生了解数学广泛 的应用领域。以此为指导, 北交大海滨学院对数学建模及 数学实验课程的教学内容进行了改革。

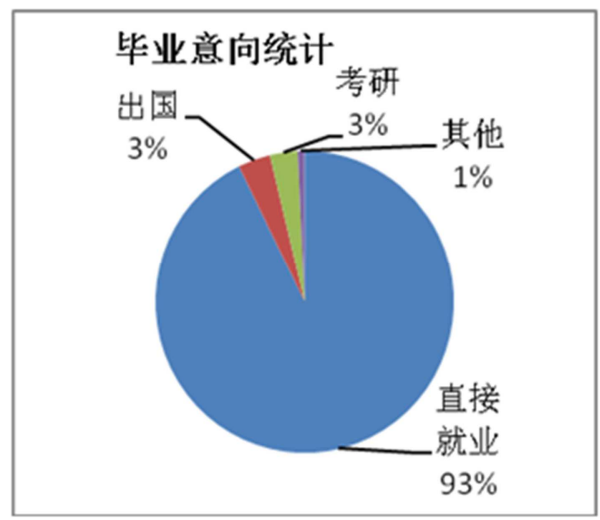

图1 毕业意向统计图。

\section{1.2. 教学内容与时俱进, 贴近学生生活}

随着社会的不断发展, 作为一门倡导创新的实践课程, 教学内容也应该与时俱进。这就要求授课教师做到三个多, 即 “多关注时事, 多思考研讨, 多与学生沟通, 了解学生 生活中的困难和问题”, 并以此为背景引出教学案例, 尽 量选取简单易懂的案例, 让学生切身体会到数学与他们的 生活息息相关。例如，通过 “椅子能否在不平的地面上放 平” 案例让学生体会如何用数学语言去描述实际问题, 但 是对于不平的地面这个背景, 现代学生们往往会理解偏颇, 所以给出案例背景时可以事先录制一段视频, 让学生对问 题的背景有一个感官的认识; 在讲解数学建模的过程和方 法时, 尽量减少语言的叙述, 而是以包饺子模型为例, 让 学生理解建立模型的过程并且提会定性和定量的思维, 培 养量化分析问题的思维; 通过让学生调研各专业入党分配 名额问题引出 “公平席位分配” 模型 [1] 的讲解, 通过让 学生调查贫困生指标的确定方法给出 “层次分析模型” 的 讲解等。

\section{2. 始终贯彻 “以学生为主” 的理念}

“以学生为主” 不仅体现在教学过程中改变以往 “教 师讲, 学生听” 的模式, 还体现在从选课, 上课, 考核各 个方面。

首先, 选课模式的改革, 遵从更多学生的意愿。曾经 数学建模和数学实验课程是与其他选修课程一样在开学 的第一个周末由学生自己登陆教务系统选择, 今年对这样 的选课模式做了改革, 体现在在上课学期的前一学期期末 即把选课通知下放到各系, 由学生自由选择报名, 并由任 课教师篮选上课名单。这样一方面避免了学生在开学初的 盲抢, 使得学生有一个了解的过程从而决定是不是选择该
课程来修, 另一方面也杜绝了某些只是为了凑学分的学生 能够选上这门课而一些真正想要学习的同学因为网络慢 等问题而抢不上课。

其次, 教学模式的改革, 让绝大多数学生能够听懂领 会每一个模型和实验。该门课程的设置目的是在普及思想, 培养兴趣, 教学内容不求多, 不求快, 而是争取用少量的 实验和模型, 让学生更深刻的体会 “用数学” 的思想。

主要方法有课程开始便利用一到两周的时间, 让学生 自由结组。课内, 以组为单位自由研讨, 教师主要起引导 作用, 多提问, 根据每一次学生的反映情况适当调整教学 计划, 因材施教; 课外, 以组为单位, 完成课后思考题及 作业。并在课上留有学生讲的时间, 学生根据自己所学专 业知识及兴趣给大家分享自己的研究成果。将课堂教学, 自助研学, 自由讨论, 课内实验, 课外实践有机结合。

再次, 考核方式的改革, 考核以学生学习情况为主导, 考核方式更自由。学生的最终成绩=平时成绩 $* 60 \%+$ 期末成 绩 $* 40 \%$ 。其中, 数学建模课程平时成绩包括课堂发言, 上 台讲解, 课后完成作业情况, 期末成绩由完成期末论文的 质量决定。数学实验课程平时成绩包括实验报告, 课堂发 言, 上台讲解, 期末成绩由期末试卷完成情况决定。

数学建模课程结课论文内容不限, 可以写一个自己完 成的小建模问题, 也可以写数学建模在自己所学专业中的 一个应用, 也可以写学习后的课程感想和收获, 唯一要求 就是必须是自己的真实实践或想法。目的是避免千篇一律 的抄袭, 通过考核了解学生的真实想法, 从而更好的促进 教学改革。将学生讲环节作为平时成绩的重要依据, 有效 促进了学生的自主学习, 培养学生发现问题, 分析问题, 解决问题的能力, 也培养了学生的表达能力。结组方式让 学生在一开始就形成团队, 互相磨合完成任务, 一方面培 养了学生们的团队协调能力, 另一方面为参加数学建模竞 赛做了准备。另外, 如遇有在课程前后参加全国各类数学 建模竞赛并完成论文尚可的同学给予附加分数, 目的是鼓 励学生们参赛, 以竞赛的形式提高学生自己学习的主动性。

\section{3. 注重数学建模思想在其他数学课程中的渗透}

数学建模是沟通现实世界和数学科学之间的桥梁, 是 数学走上应用的必经之路 [5], 但是作为一门基础学科, 数学又是及其抽象的, 如果将抽象的数学教学与实际应用 隔离开来, 就必然会造成学生不会用数学, 不知为何学数 学的现象存在。而数学建模和数学实验课程课时短, 时间 紧, 如果只是在选修课上灌输数学的 “应用性”, 则是远 远不够的。本着让更多学生了解数学建模思想, 掌握数学 建模思维的目的, 结合几年的教学经验和独立学院学生的 学习特点, 专门编写了符合独立学院学生的一套大学数学 基础教材, 包括《高等数学 I》, 《高等数学 $\mathrm{II}$ 》, 《概率 论与数理统计》, 《线性代数》等, 教材更加注重应用, 淡化了数学推导, 每一个新概念的引入都尽量从实际背景 出发, 将抽象的数学概念与实际联系起来, 注重启发式教 学, 同时在掌握数学概念和专业知识以后, 又将其延伸到 新的应用中去, 充分体现了数学建模的思想。例如, 《线 性代数》第一章矩阵概念的引例, 就是建模思想的融入。 在每一章最后, 专门添加了应用一节。 
如第二章最后给出的应用问题是 “调味品配置问题” [2], 某调料公司用五种原料来制造多种调味品。表格形 式给出了三种调味制品 $A, B, C$ 每包中所需各种成分的量。 在这样的背景下给出问题:

（1）为了能配制出其余几种调味品, 这位顾客要购 买的最少的调味品的种类是多少, 并写出所需最少调味品 的集合。

(2) 在 (1) 中得到的最小调味品集合是否唯一? 若 不唯一, 给出另外的情况。

(3) 利用在 (1) 中找到的最小调味品集合, 配置一 种新的调味品。

这三个问题, 本质就是考察学生对于向量组中最大无 关组概念及秩的理解, 以及给定一个向量如何判断它是否 能有已知向量组线性表示的问题。

数学建模及实验思想在其他课程中的渗透要求教师 和学生明白数学建模的全过程, 培养双向翻译的能力 [5], 既把现实问题用数学语言去描述, 在将数学解答的过程和 结论翻译成现实问题的结论, 这进一步要求教师在日常教 学中不仅要熟练掌握需要传授的课堂知识, 也要求教师对 所教授课程的应用和推广有深而广的了解。

\section{4. 利用微课, 微信等多种教学模式, 搞好课外实践环 节}

\subsection{1. 创建优质微课, 实现翻转课堂}

数学建模课程以案例教学为主, 而如果每一个案例都 利用课上时间让学生去思考去探讨, 显然时间不够, 但如 果不留时间供学生探讨和思考, 又会造成学习不深入, 理 解不透彻, 无法领会建模的灵魂。翻转课堂教学模式是指 在信心技术的支持下, 以教师录制的微课视频为载体, 学 生在课外自主完成知识的学习, 而课堂变成了教师和学生 之间互动的场所, 从而达到更好的教育效果 [13], 显然这 一种是更适合数学建模和数学实验课程的教学模式, 基于 此, 可以选取一些课程知识背景, 重要知识点, 或者一些 简单有趣的经典建模案例, 将其制作成 10-20分钟的短视 频, 供学生课下研究和学习, 学生带着自己的思考和问题 上课, 课堂主要用于与学生探讨和互动, 大大提高了课堂 的利用效率, 也增加了授课效果。

例如, 将 “夫妻过河模型” 制作成微课, 在第一次课 后让学生们课下学习和思考。在第二次上课时, 邀请同学 们对所学案例进行分析和讲解, 并由其他同学给出自己的 思路和想法。在讲解含有测试分析方法的模型时, 经常用 到最小二乘法求拟合曲线的参数问题, 将最小二乘法做成 微课形式供学生课下学习, 并且在课上给出几个不完善的 案例让学生自己利用最小二乘法完善问题。

\subsection{2. 建立微信、QQ等交流群, 方便答疑和交流}

微信, QQ显然成为现在学生必不可少的生活交流方 式, 作为一名年轻教师, 不应该抵触这类事物, 而是应 该通过建立学生习惯的交流方式, 享受新技术为教学带 来的方便。一方面, 方便为学生及时答疑, 另一方面, 又方便了学生之间的交流和学习, 并且还有助于学生在 课程结束之后的进一步研究和学习。比如, 在上数学实
验课的时候, 就通过面对面建群方式建立了学习交流群, 在上课之时, 同学们利用交流群自由结组和分享自己在 学习过程中的疑惑或问题, 在课程结束之后, 有部分同 学讲所学内容应用到自己的所学专业之中, 因此产生的 问题也在群里得到了解决。

\section{4. 结束语}

通过以上课程实践, 让更多的学生体会到了数学的乐 趣和用处, 独立学院的学生入学成绩比本科二批学生要低 60 80 分, 并且独立学院学生个体之间的差异也较大 [15], 因为这样的特点, 在教学上我们不应该一心求学生考试获 得多高的成绩或者参加什么比赛获得多少奖项, 而是更加 注重学生对于数学内涵的理解, 对于用数学思想的体会。 据了解, 北京交通大学海滨学院的学生已经有越来越多的 同学开始主动学习数学建模和软件操作, 由学生自己举办 的数学建模协会和数学协会在逐步完善, 数学实验室建立 完成, 已经投入使用。当然, 大学数学应用能力教育模式 探索还是一个长期艰巨的任务, 任何方法和手段都不可能 立竿见影, 我们只有认真准备, 不解钻研, 讲好每一堂课, 每一个知识点, 想学生之所想, 爱学生, 爱教学, 为学校 培养更多优秀人才作出贡献。

\section{致谢}

本文为校内教改项目《大学数学应用能力教育模式探 索及教学实践改革》的阶段性成果之一。

\section{参考文献}

[1] 王兵团. 数学建模基础 [M]. 北京: 清华大学出版社, 2004: $12-14$ 。

[2] 陈丙振等. 线性代数 [M]. 北京: 机械工业出版 社, 2014. 1:49-51。

[3] 王兵团等. Matlab 与数学实验 [M]. 北京: 中国铁道出版 社, 2014. 8:63-64。

[4] 叶其孝. 把数学建模数学实验的思想和方法融入高等数学 课的教学中去 $[J]$. 工程数学学报, 2003 年, $20(8): 3-13$ 。

[5] 姜启源. 一项成功的高等教育改革实践 数学建模教学与竞 赛活动的探索与实践 [J]. 中国高教研究, 2011年, 12: 80-83。

[6] 张鸿雁. 关于数学实验与数学建模_课程教学改革中的几个 问题的探讨 $[J]$. 数学理论与应用, 2002 年, $22(4): 9-11$ 。

[7] 张文博等. 数学建模与数学实验课程调查报告 $[\mathrm{J}]$. 工程数 学学报, 2015年, 1: 37-54。

[8] 李永艳, 李晓玲. 将数学建模与独立学院的数学教学相结 合 $[\mathrm{J}]$. 科技视界, 2014年, 30：65-67。

[9] 李晓玲, 杨慧贤. 浅谈独立学院数学建模教学的探索与研 究 [J]. 价值工程, 2014年, 15: 259-260。 
[10] 罗卫民等. 数学实验与数学建模课程教学改革 $[J]$. 工程数 学学报, 2005年, 6: 110-112。

[11] 薛长虹, 于凯. 数学建模课程教学方式探讨 $[\mathrm{J}]$. 大学数学 2007年第23卷: 141-143。

[12] 韦程东. 基于微课的数学建模教学模式研究 [J]. 广西师范 学院院报 2015年第32卷: 105-108。
[13] 徐静. 数学建模课程的翻转课堂教学 [J]. 高师理科学刊 2014年第34卷:88-92。

[14] 北京交通大学海滨学院“十三五”发展规划编制工作方案。

[15] 袁剑波. 独立学院应用型人才培养模式创新与实践 $[\mathrm{J}]$. 高 等工程教育研究 2011年第2期: 118-123。

[16] 陈奕. 数学实验综述 $[J]$. 学科探索 2014年5月:57-58。 